Original Article

\title{
Clinical physical therapists research activity reality and barriers to their utilizing research findings
}

\author{
Kyungyeon Park, PhD, RN¹), Boram Choi, PhD, PT ${ }^{2)}$, Dongwook Han, PhD, $\mathrm{PT}^{2) *}$ \\ 1) Department of Nursing, College of Health and Welfare, Silla University, Republic of Korea \\ 2) Department of Physical Therapy, College of Health and Welfare, Silla University: 700 beon-gil, \\ 140 Baegyang-daero, Sasang-gu, Busan 617-736, Republic of Korea
}

\begin{abstract}
Purpose] This research study was performed to investigate the barriers to using the research findings of physical therapists on evidence-based practice. [Subjects] The subjects of this research were physical therapists employed by hospitals that agreed to cooperate with the research in B city. [Methods] A questionnaire made up of 6 research items, 8 physical therapist items, 6 presentation items, and 8 setting items, for a total of 28 items, was distributed. The responses were scored so the higher result scores indicate a higher barrier level to using research findings. Differences in barrier levels related to the likelihood of therapists using research findings in their practice varied according to the general characteristics of the result as according to the t-test and ANOVA. Scheffe's test was used as a post hoc test. [Results] The analysis of 158 returned questionnaires revealed that there were significant relationships between the age, educational level, and professional satisfaction of the therapists and the barriers to using research finding. Significant relationships were also found between the items of "Research participation in clinical research", "Frequency of reading research articles", and "Support of manager to use research" and the barrier level. No relationship was demonstrated between the recognition level of evidence-based practice and the performance level with the barrier score to using research findings. [Conclusion] This study demonstrated that to improve the utilization of research findings, there is a need to provide therapists with continual education and opportunities to participate in research, and environments and ways in which the research results can be given practical applications.
\end{abstract}

Key words: Barriers, Research findings, Evidence-based practice

(This article was submitted Feb. 13, 2015, and was accepted Mar. 24, 2015)

\section{INTRODUCTION}

"Evidence-based practice" (EBP) conducted in the health and medical field refers to clinical decision-making based on the best available external clinical evidence, and on individual clinical expertise ${ }^{1)}$. The health and medical profession is a practical field of scholarship; hence practical technique, theory, and research should all be developed together. When the newest information from systematic research is applied in the clinical field, it can be referred to as client-centered medical service ${ }^{2)}$. However, the use of research findings in the practical field is not very common. Smith ${ }^{3)}$ stated that only $15 \%$ of clinical services use objective evidence based on research. Gwendolijne et al. ${ }^{4)}$ stated that, although doctors practicing in hospitals have a positive attitude towards research, only $5 \%$ of them actually make use of scientific research findings when making clinical decisions. From these results, we can infer that there are barriers to ap-

*Corresponding author. Dongwook Han (E-mail: dwhan@ silla.ac.kr)

C2015 The Society of Physical Therapy Science. Published by IPEC Inc. This is an open-access article distributed under the terms of the Creative Commons Attribution Non-Commercial No Derivatives (by-ncnd) License $<$ http://creativecommons.org/licenses/by-nc-nd/3.0/> plying scientific research findings in the clinical field. Some difficulties present themselves regarding the application of research: for example, lack of time because of the overload of work; environmental factors, such as lack of organizational support; lack of understanding of evidence based on practice and research; personal factors, such as the lack of ability to search for study articles; research factors regarding the quality of published articles; and how the results of the research are communicated ${ }^{5-7)}$. However, because there are numerous professions within the health and medical field, it is very important to research the barriers according to the types of professions that have not been actively making use of research materials. Research has been performed on occupational therapists and on nurses ${ }^{5,8)}$, but no research has been performed specifically on physical therapists. Since practical physical therapy is performed on patients in the clinical environment, significant evidence-based practice also needs to be conducted in the clinical environment. The application of evidence-based practice is an important part of clinical decision making when providing evaluation of rehabilitation and therapeutic services ${ }^{9)}$.

Therefore, the purpose of this research was to investigate the most effective way that evidence-based practice can be performed in conjunction with the actual activities of physical therapists. Investigation also needed regarding the differences in barriers to the use of research findings by physical 
Table 1. Barriers to using research findings $(\mathrm{N}=158)$

\begin{tabular}{|c|c|c|c|c|c|c|}
\hline $\begin{array}{l}\text { Type of } \\
\text { barrier } \\
\text { (Mean) }\end{array}$ & Barrier items & Mean & SD & $\mathrm{N}^{*}$ & $\%$ & $\begin{array}{l}\text { Rank } \\
\text { order }\end{array}$ \\
\hline \multirow{6}{*}{$\begin{array}{l}\text { Research: } \\
\text { Qualities of the } \\
\text { research } \\
(2.3)\end{array}$} & The literature reports conflicting results & 2.2 & 0.6 & 40 & 25.3 & 19 \\
\hline & The research has methodological inadequacies & 2.2 & 0.7 & 44 & 27.8 & 15 \\
\hline & The research has not been replicated & 2.4 & 0.7 & 67 & 42.4 & 8 \\
\hline & The conclusions drawn from the research are not justified & 2.1 & 0.5 & 33 & 20.9 & 23 \\
\hline & Research reports/articles are not published fast enough & 2.2 & 0.7 & 44 & 27.8 & 15 \\
\hline & The physical therapist is uncertain whether to believe the results of the research & 2.5 & 0.8 & 83 & 52.5 & 6 \\
\hline \multirow{8}{*}{$\begin{array}{l}\text { Physical } \\
\text { therapist: The } \\
\text { physical thera- } \\
\text { pist's research } \\
\text { value, skills, and } \\
\text { awareness } \\
\text { (2.1) }\end{array}$} & The physical therapist is unwilling to change/try new ideas & 2.1 & 0.8 & 47 & 29.7 & 21 \\
\hline & The physical therapist feels the benefits of changing practice will be minimal & 2.2 & 0.7 & 47 & 29.7 & 19 \\
\hline & The physical therapist does not see the value of research for practice & 1.9 & 0.6 & 14 & 8.9 & 28 \\
\hline & The physical therapist sees little benefit for self & 2.0 & 0.7 & 27 & 17.1 & 27 \\
\hline & There is not a documented need to change practice & 2.0 & 0.7 & 34 & 21.5 & 26 \\
\hline & The physical therapist is unaware of the research & 2.3 & 0.8 & 69 & 43.7 & 11 \\
\hline & $\begin{array}{l}\text { The physical therapist is isolated from knowledgeable colleagues with whom to } \\
\text { discuss the research }\end{array}$ & 2.3 & 0.8 & 61 & 38.6 & 13 \\
\hline & The physical therapist does not feel capable of evaluating the quality of the research & 2.3 & 0.86 & 61 & 38.6 & 13 \\
\hline \multirow{6}{*}{$\begin{array}{l}\text { Presentation: } \\
\text { Presentation and } \\
\text { accessibility of } \\
\text { the research } \\
(2.5)\end{array}$} & The research is not reported clearly and readably & 2.5 & 0.8 & 84 & 53.2 & 5 \\
\hline & The relevant literature is not compiled in one place & 2.3 & 0.7 & 56 & 35.4 & 12 \\
\hline & Implications for practice are not made clear & 2.7 & 0.8 & 110 & 69.6 & 1 \\
\hline & Statistical analyses are not understandable & 2.4 & 0.7 & 71 & 44.9 & 9 \\
\hline & The research is not relevant to the physical therapist's practice & 2.4 & 0.7 & 69 & 43.7 & 9 \\
\hline & Research reports/articles are not readily available & 2.4 & 0.8 & 78 & 49.4 & 7 \\
\hline \multirow{8}{*}{$\begin{array}{l}\text { Setting: Setting } \\
\text { barriers and } \\
\text { limitation } \\
(2.3)\end{array}$} & The physical therapist feels results are not generalizable to own setting & 2.7 & 0.8 & 101 & 63.9 & 2 \\
\hline & $\begin{array}{l}\text { The physical therapist does not feel she/he has enough authority to change patient } \\
\text { care procedures }\end{array}$ & 2.1 & 0.7 & 43 & 27.2 & 24 \\
\hline & The physical therapist does not have time to read research & 2.2 & 0.7 & 47 & 29.7 & 15 \\
\hline & The facilities are inadequate for implementation & 2.6 & 0.8 & 92 & 58.2 & 3 \\
\hline & There is insufficient time on the job to implement new ideas & 2.5 & 0.8 & 87 & 55.1 & 4 \\
\hline & Administration will not allow implementation & 2.1 & 0.7 & 36 & 22.8 & 21 \\
\hline & Physicians will not cooperate with implementation & 2.2 & 0.7 & 43 & 27.2 & 15 \\
\hline & Other staff are not supportive of implementation & 2.0 & 0.6 & 21 & 13.3 & 25 \\
\hline
\end{tabular}

Total

(2.3)

*Reporting item as a moderate or great barrier, †Barriers were classified as being characteristics of physical therapist, the setting, the research, or its presentation

therapists in evidence-based practice.

\section{SUBJECTS AND METHODS}

The subjects of this research were physical therapists employed by hospitals that agreed to cooperate with the research in B city. A questionnaire survey was conducted in the period from September 2014 to October 2014. The participants were asked to fill up their response in structure questionnaires. Two hundred copies of the questionnaire were distributed, of which 163 copies were completed and returned, giving a recovery rate of $81.5 \%$. The purpose of the research was explained to the participants, and instructions were given on how to answer the questionnaire. This study complied with the ethical principles of the Declaration of Helsinki and all participants signed a written consent that explained that participation was voluntary, the withdrawal procedure, and confidentiality of the information. It was stipulated that the information collected by the questionnaire would not be used for purposes other than the research for this project. To examine the barriers to using research findings, the Barriers to Research Utilization Scale that was founded by Funk et al. ${ }^{10)}$ was used. The questionnaire was made up of 6 research items, 8 physical therapist items, 6 presentation items, and 8 setting items, a total of 28 items. For every items, a Likert scale was used. Responses ranged from 1 point indicating "not at all" to 4 points indicating "very much". A higher score indicated a higher barrier level to using research findings. Cronbach's alpha of reliability was 0.93 . The content validity of the questions was tested using an expert panel $(\mathrm{n}=5)$. Each expert panel member evaluated the items for content validity on a 5-point scale. 
Table 2. Differences in barriers to using research findings by characteristics of participants $(\mathrm{N}=158)$

\begin{tabular}{|c|c|c|c|}
\hline Variables & Division & $\mathrm{N}(\%)$ & Mean \pm SD \\
\hline \multirow{2}{*}{ Gender } & Male & $103(65.2)$ & $2.2 \pm 0.5$ \\
\hline & Female & $55(34.8)$ & $2.3 \pm 0.3$ \\
\hline \multirow{4}{*}{ Age (years)* } & $\leq 24$ & $19(12.0)$ & $2.5 \pm 0.3$ \\
\hline & $25-29$ & $61(38.6)$ & $2.3 \pm 0.5$ \\
\hline & $30-34$ & $52(32.9)$ & $2.2 \pm 0.5$ \\
\hline & $35 \leq$ & $26(16.5)$ & $2.4 \pm 0.3$ \\
\hline \multirow{3}{*}{ Education*† } & College $^{\mathrm{a}}$ & $39(24.7)$ & $2.5 \pm 0.4$ \\
\hline & University $^{\mathrm{b}}$ & $72(45.6)$ & $2.2 \pm 0.4$ \\
\hline & Graduate school or more & 47 (29.7) & $2.2 \pm 0.4$ \\
\hline \multirow{4}{*}{ Hospital type } & University hospital & $51(32.3)$ & $2.3 \pm 0.4$ \\
\hline & General hospital & $81(51.3)$ & $2.2 \pm 0.4$ \\
\hline & Rehabilitation hospital & $21(13.3)$ & $2.5 \pm 0.3$ \\
\hline & Clinic & $5(3.2)$ & $2.3 \pm 0.5$ \\
\hline \multirow{3}{*}{ Working place } & Modality room & $27(17.1)$ & $2.2 \pm 0.5$ \\
\hline & Exercise room & $116(73.4)$ & $2.3 \pm 0.4$ \\
\hline & Manual therapy room & $15(9.5)$ & $2.3 \pm 0.5$ \\
\hline \multirow{3}{*}{ Assigned patient } & Musculoskeletal & $58(36.7)$ & $2.3 \pm 0.5$ \\
\hline & Adult neurology & $86(54.4)$ & $2.3 \pm 0.4$ \\
\hline & Pediatric neurology & $14(8.9)$ & $2.2 \pm 0.2$ \\
\hline \multirow{4}{*}{ Career (months) } & $\leq 12$ & $23(14.6)$ & $2.2 \pm 0.6$ \\
\hline & $13-36$ & $34(21.5)$ & $2.4 \pm 0.4$ \\
\hline & $37-60$ & $28(17.7)$ & $2.3 \pm 0.5$ \\
\hline & $61 \leq$ & $73(46.2)$ & $2.2 \pm 0.4$ \\
\hline \multirow{4}{*}{ Professional satisfaction* $*$} & Very dissatisfied ${ }^{\mathrm{a}}$ & $4(2.5)$ & $2.2 \pm 0.1$ \\
\hline & Dissatisfied $^{\mathrm{b}}$ & $34(21.5)$ & $2.5 \pm 0.3$ \\
\hline & Satisfied $^{c}$ & $107(67.7)$ & $2.2 \pm 0.4$ \\
\hline & Very satisfied $^{\mathrm{d}}$ & $13(8.2)$ & $2.0 \pm 0.5$ \\
\hline
\end{tabular}

All item scores were greater than 0.80 . The range of the content validity index (CVI) was 0.80 to 1.0 . The average scale content validity index (CVI) was 0.92 . So, the content validity of the Barriers to Research Utilization Scale used in this study was supported by the content validity index (CVI). SPSS (ver. 21.0) was used to conduct statistical analyses, and the significance level used in the analysis was 0.05 . Descriptive statistics were calculated for general and clinical characteristics, barriers to using research findings, research related activities, and recognition and performance of evidence-based practice. The differences in the barrier level to using research findings according to the general characteristics of the result were analyzed using the t-test, and ANOVA, and Scheffe's test was used as a post hoc test ${ }^{11)}$.

\section{RESULTS}

The results of the barriers to using research findings by the physical therapists in a hospital environment are shown in Table 1. The average score of the barrier level to using research findings was 2.3. The greatest barrier among the research, physical therapy, presentation and setting categories was presentation, 2.5 . The physical therapy category had the lowest score, 2.1. The average score of the items was 2.7. "Implications for practice are not made clear" was the biggest barrier to using research findings. This was followed by "The physical therapist feels results are not able to be generalized to his/her own setting" at 2.7. On the other hand, the average barrier scores that were $\leq 2$ included "The physical therapist does not see the value of research for practice" at 1.9; "The physical therapist sees little benefit for self" was 2.0; and "There is not a documented need to change practice" was 2.0. These three items are in the physical therapist category. The effects of physical therapist's general characteristics and clinical characteristics on the barriers to using research findings are shown in Table 2. Age $(p<0.05)$, educational level $(\mathrm{p}<0.05)$, and professional satisfaction $(p<0.05)$ all demonstrated significant relationships with the barriers to using research findings. Participants 24 years old and below had the highest barrier score, while participants in the 30-34 year age bracket had the lowest barrier score. In the educational level category, college graduates had significantly higher barrier scores than those with a bachelor's or master's degree. In the case of professional satisfaction, the barrier score was lowest among those who reported the highest satisfaction; on the other hand, the barrier score was 
Table 3. Barriers to using research findings by research-related activities of participants $(\mathrm{N}=158)$

\begin{tabular}{|c|c|c|c|}
\hline Variables & Division & $\mathrm{N}(\%)$ & Mean \pm SD \\
\hline \multirow{2}{*}{ Membership of physical therapy academy } & Yes & $153(96.8)$ & $2.37 \pm 0.4$ \\
\hline & No & $5(3.2)$ & $2.3 \pm 0.2$ \\
\hline \multirow{4}{*}{ Division of membership academy } & Musculoskeletal & $47(29.7)$ & $2.4 \pm 0.4$ \\
\hline & Neurology & $103(65.2)$ & $2.2 \pm 0.4$ \\
\hline & Others & $3(1.9)$ & $2.2 \pm 0.1$ \\
\hline & None & $5(3.2)$ & $2.3 \pm 0.2$ \\
\hline \multirow{2}{*}{ Attendance of academic conference in recent 2 years } & Yes & $144(91.1)$ & $2.3 \pm 0.4$ \\
\hline & No & $14(8.9)$ & $2.3 \pm 0.4$ \\
\hline \multirow{2}{*}{ Presentation in academic conference } & Yes & $44(27.8)$ & $2.3 \pm 0.4$ \\
\hline & No & $114(72.2)$ & $2.3 \pm 0.4$ \\
\hline \multirow{2}{*}{ Publication of research article } & Yes & $42(26.6)$ & $2.2 \pm 0.5$ \\
\hline & No & $116(73.4)$ & $2.3 \pm 0.8$ \\
\hline \multirow{2}{*}{ Research participation in clinical research* } & Yes & $55(34.8)$ & $2.2 \pm 0.4$ \\
\hline & No & $103(65.2)$ & $2.3 \pm 0.4$ \\
\hline \multirow{5}{*}{ Frequency of reading research article* ${ }^{*} \dagger$} & Never $^{\mathrm{a}}$ & $19(12.0)$ & $2.5 \pm 0.3$ \\
\hline & Several times per a year ${ }^{b}$ & $81(51.3)$ & $2.3 \pm 0.4$ \\
\hline & Monthly ${ }^{\mathrm{c}}$ & $23(14.6)$ & $2.1 \pm 0.5$ \\
\hline & Biweekly ${ }^{\mathrm{d}}$ & $13(8.2)$ & $2.1 \pm 0.2$ \\
\hline & Weeklye & $22(13.9)$ & $2.1 \pm 0.5$ \\
\hline \multirow{2}{*}{ Taken research course } & Yes & $104(65.8)$ & $2.2 \pm 0.4$ \\
\hline & No & $54(34.2)$ & $2.3 \pm 0.4$ \\
\hline \multirow{2}{*}{ Support of manager to use research* } & Yes & $47(29.7)$ & $2.1 \pm 0.5$ \\
\hline & No & $111(70.3)$ & $2.3 \pm 0.4$ \\
\hline \multirow{2}{*}{ Experience of participating research conference } & Yes & $81(51.3)$ & $2.2 \pm 0.4$ \\
\hline & No & $77(48.7)$ & $2.3 \pm 0.4$ \\
\hline
\end{tabular}

$* \mathrm{p}<0.05$

$\dagger: \mathrm{a}>\mathrm{e}$ by post hoc test

the highest among those who reported the lowest satisfaction (Table 2). The research-related activities of the physical therapists regarding the barrier level to using research findings are shown in Table 3. There was a significant relationship between the barrier level and "Research participation in clinical research" $(\mathrm{p}<0.05)$, "Frequency of reading research articles" ( $p<0.05)$, and "Support of manager to use research" $(\mathrm{p}<0.05)$. The analysis revealed that the barrier score of participants in clinical research was lower than the barrier score of the participants who did not participate in the research; and those who never read study articles had a higher barrier score than those who read study articles weekly. Furthermore, those who answered that they had no support from their managers to use research in the physical therapy room had higher barrier scores than those who received managerial support. The effects of evidence-based treatment according to recognition and performance of physical therapists on the barrier factors to using research findings are shown in Table 4. The recognition level of evidence-based practice $(p<0.05)$ and the performance level $(p<0.05)$ showed differences the barrier score to using research finding.

\section{DISCUSSION}

Among the barriers to using research findings, the item
Table 4. Differences in barriers to using research findings by level of recognition and performance for evidencebased physical therapy $(\mathrm{N}=158)$

\begin{tabular}{llcc}
\hline Variables & Division & $\mathrm{N}(\%)$ & Mean \pm SD \\
\hline & Never $^{\mathrm{a}}$ & $9(5.7)$ & $2.1 \pm 0.4$ \\
Recognition*† $^{*}$ & A little $^{\mathrm{b}}$ & $66(41.8)$ & $2.4 \pm 0.4$ \\
& Moderate $^{\mathrm{c}}$ & $58(36.7)$ & $2.3 \pm 0.3$ \\
& Very well $^{\mathrm{d}}$ & $25(15.8)$ & $2.1 \pm 0.5$ \\
& Never $^{\mathrm{a}}$ & $8(5.1)$ & $2.2 \pm 0.7$ \\
Performance** $^{*}$ & A little $^{\mathrm{b}}$ & $53(33.5)$ & $2.5 \pm 0.3$ \\
& Moderate $^{\mathrm{c}}$ & $74(46.8)$ & $2.2 \pm 0.3$ \\
& Very well $^{\mathrm{d}}$ & $23(14.6)$ & $1.9 \pm 0.5$ \\
\hline
\end{tabular}

$\dagger: \mathrm{b}>\mathrm{d}$ by post hoc test, $\uparrow: \mathrm{b}>\mathrm{c}, \mathrm{d}, \mathrm{c}>\mathrm{d}$ by post hoc test

that had the highest barrier score was "Implications for practice are not made clear" followed by "The physical therapist feels the results are not generalizable to his/her own setting". These results are very similar to those of a study in which nurses were subjects of the research ${ }^{5}$. The physical therapist category score was the lowest at 2.12. Generally, scores of 2 points and below are not considered barriers - "No barri- 
ers to using research findings". The items scored at 2 points and below included "The physical therapist does not see the value of research for practice", "The physical therapist sees little benefit for self", and "There is no documented need to change practice". These 3 items are in the physical therapist category. The low barrier score of the physical therapist category (which includes the value and recognition of the physical therapist regarding the research) has a very positive effect on the use of this research. Because physical therapists are the subject of this research, changes in value and recognition on the part of the therapists is not easy. In contrast, items in the research, presentation and setting categories could be corrected in a short period if efforts were made.

Analysis of the results of barriers to using research findings regarding the general characteristics of the physical therapists revealed that participants aged 24 years old and younger had the highest barrier scores. It is probable that this is because therapists who are 24 years old and younger usually depend heavily on guidelines in their practice, so they are less inclined to use research findings. Physical therapists who are 34 years old and older also had a high barrier score because their greater clinical experience reduces their inclination to use research findings in the decision making process on behalf of their patients. This result parallels the results of the research of Cameron et al. ${ }^{12)}$ and Dysart \& Tomlin $^{13)}$. Melnyk et al. ${ }^{14)}$ also stated that as the therapists have more experience when their clinical careers, they tend to rely more upon their own existing knowledge or experience in treating their patients. As regards educational level, the college graduates had higher barrier scores than those who had graduated from university or postgraduate school. Compared to the curriculum of junior colleges, it is understood that the curriculum of universities and other higher education centers weights the importance of reading study articles, understanding research methodologies, and understanding the relationship between practice and research. Hence, to improve the quality of physical theory, and to apply evidence-based physical therapy, there needs to be arrangements to educate physical therapists to read, study, and evaluate study articles. In addition, the physical therapists who reported satisfaction in their job had lower barrier scores than those who were not satisfied with their jobs. Therefore, it is desirable to improve the job satisfaction of physical therapists, rather than simply emphasizing the application of study results. The results demonstrate that the more experience physical therapists had in clinical research participation, the greater their frequency of reading research articles, and the higher the level of support they received from managers to use the research, the lower the barrier score becomes. However, the physical therapists who participated in clinical research amounted to only $34.8 \%$ of the sample, significantly lower than physical therapists in the Netherlands, $61.7 \%{ }^{4)}$. The percentage of physical therapists participating in clinical research was also lower than the percentage of occupational therapists at $40.2 \%^{8}$ ). This demonstrates the need for active participation of therapists in the research. Among the physical therapists who were the subjects of this research, $52.5 \%$ answered that they were aware of evidence-based practice, and $61.4 \%$ of them were putting it into practice. Hence the nurses cited previously had relatively higher levels of recognition and performance ${ }^{5)}$. Those physical therapists who had high recognition and performance of evidence-based practice demonstrated a lower barrier level to using research findings, indicating that more emphasis should be placed on education to improve the recognition of evidence-based practice for the application of research results.

From the results described above, it can be concluded that the age, educational level, and professional satisfaction of physical therapists are major factors influencing barriers to using research findings. Among the items that were related to research, participation in clinical research, frequency of reading research articles, and support of managers to use research, affected the barrier scores. Hence, we conclude that to improve the utilization of research findings, there is a need to provide continuous education, and more opportunities should be created to allow participation in research and environments where research results can be applied.

\section{REFERENCES}

1) Sackett DL, Rosenberg WM, Gray JA, et al.: Evidence based medicine: what it is and what it isn't. BMJ, 1996, 312: 71-72. [Medline] [CrossRef]

2) Egan M, Dubouloz CJ, von Zweck C, et al.: The client-centered evidence based practice in occupational therapy. Can J Occup Ther, 1998, 65: 136143. [CrossRef]

3) Smith R: Where is the wisdom...? BMJ, 1991, 303: 798-799. [Medline] [CrossRef]

4) Scholten-Peeters GG, Beekman-Evers MS, van Boxel AC, et al.: Attitude, knowledge and behaviour towards evidence-based medicine of physical therapists, students, teachers and supervisors in the Netherlands: a survey. J Eval Clin Pract, 2013, 19: 598-606. [Medline] [CrossRef]

5) Oh EG, Oh HJ, Lee YJ: [Nurses' research activities and barriers of research utilization]. Taehan Kanho Hakhoe Chi, 2004, 34: 838-848. [Medline]

6) Salbach NM, Jaglal SB, Korner-Bitensky N, et al.: Practitioner and organizational barriers to evidence-based practice of physical therapists for people with stroke. Phys Ther, 2007, 87: 1284-1303. [Medline] [CrossRef]

7) Sitzia J: Barriers to research utilisation: the clinical setting and nurses themselves. Intensive Crit Care Nurs, 2002, 18: 230-243. [Medline] [CrossRef]

8) Kang DH, Lee JE, Kim JK: Perception of Korean occupational therapists on evidence-based occupational therapy. J Korean Soc Occup Ther, 2007, 15: $13-23$.

9) Christiansen C, Lou JQ: Ethical considerations related to evidence-based practice. Am J Occup Ther, 2001, 55: 345-349. [Medline] [CrossRef]

10) Funk SG, Champagne MT, Wiese RA, et al.: Barriers to using research findings in practice: the clinician's perspective. Appl Nurs Res, 1991, 4: 90-95. [Medline] [CrossRef]

11) Lee MG, Hwang JS, Seo BD, et al.: The effects of the core muscle release technique on scoliosis. J Phys Ther Sci, 2013, 25: 445-448. [CrossRef]

12) Cameron KA, Ballantyne S, Kulbitsky A, et al.: Utilization of evidencebased practice by registered occupational therapists. Occup Ther Int, 2005, 12: 123-136. [Medline] [CrossRef]

13) Dysart AM, Tomlin GS: Factors related to evidence-based practice among U.S. occupational therapy clinicians. Am J Occup Ther, 2002, 56: $275-$ 284. [Medline] [CrossRef]

14) Melnyk BM, Fineout-Overholt E, Hockenberrry M, et al.: Improving healthcare and outcomes for high-risk children and teens: formation of the National Consortium for Pediatric and Adolescent Evidence-Based Practice. Pediatr Nurs, 2007, 33: 525-529. [Medline] 